\title{
Temperaturas de secagem na integridade física, qualidade fisiológica e composição química de sementes de arroz ${ }^{1}$
}

\author{
Nilson Lemos de Menezes ${ }^{2}$, Leandro Lourenço Pasqualli³, \\ Ana Paula Piccinin Barbieri ${ }^{3}$, Maquiel Duarte Vidal ${ }^{3}$, Gerusa Massuquini Conceição ${ }^{3}$
}

\begin{abstract}
Drying temperatures on

physical integrity, physiological quality and chemical composition of rice seeds

The drying of seeds is essential for its production process, however, the temperature used can affect seeds quality. This study aimed at evaluating the effect of different temperatures on physical integrity, physiological quality and chemical composition of rice seeds. Four lots were arranged for each cultivar, being dried with the aid of the stationary method, by using the following temperatures: $32^{\circ} \mathrm{C}, 38^{\circ} \mathrm{C}, 44^{\circ} \mathrm{C}$ and $50^{\circ} \mathrm{C}$. After each drying treatment, the physical integrity of seeds was analyzed, by evaluating its moisture content and fissures percentage. Physiological quality was evaluated with the aid of the germination test, first counting, electrical conductivity, accelerated aging, cold test, total length and dry mass of seedlings. The chemical composition of seeds was determined by evaluating their dry mass, crude protein and fiber and ethereal extract. The drying temperatures affected seeds quality, and when they increased $\left(32-50^{\circ} \mathrm{C}\right)$, the percentage of fissures in irrigated rice seeds also increased. Drying temperatures of $32^{\circ} \mathrm{C}$ and $38^{\circ} \mathrm{C}$ allowed the expression of seed quality, while the temperature of $50^{\circ} \mathrm{C}$ reduced its physiological potential.
\end{abstract}

KEY-WORDS: Oryza sativa L.; seeds chemical composition; seeds vigor.

\section{INTRODUÇÃO}

O Brasil é o principal produtor de arroz, no continente americano, destacando-se entre os dez maiores produtores mundiais, com produção superior a 12 milhões de toneladas, o que representa, aproximadamente, $1,8 \%$ do total mundial e cerca de $50 \%$ da produção das Américas (Embrapa 2009).

Nos últimos anos, o aumento da produção mundial não tem sido suficiente para compensar o

\section{RESUMO}

A secagem de sementes é uma operação indispensável no processo de produção, porém, a temperatura utilizada pode afetar a qualidade das sementes produzidas. Este trabalho objetivou avaliar o efeito de diferentes temperaturas de secagem na integridade física, qualidade fisiológica e composição química de sementes de arroz irrigado. Formaram-se quatro lotes de cada cultivar, os quais foram secos pelo método estacionário, utilizando-se as seguintes temperaturas: $32^{\circ} \mathrm{C}, 38^{\circ} \mathrm{C}, 44^{\circ} \mathrm{C}$ e $50^{\circ} \mathrm{C}$. Após os tratamentos de secagem, avaliou-se a integridade física das sementes, por meio do teor de umidade e da percentagem de fissuras. A qualidade fisiológica foi determinada com o auxílio de teste de germinação, primeira contagem, condutividade elétrica, envelhecimento acelerado, teste de frio, comprimento total e fitomassa seca de plântula. A composição química das sementes foi avaliada por meio das frações massa seca, proteína e fibra bruta e extrato etéreo das sementes. As temperaturas de secagem afetaram a qualidade das sementes, e o aumento da temperatura, na secagem $\left(32-50^{\circ} \mathrm{C}\right)$, aumentou, também, a percentagem de fissuras nas sementes de arroz irrigado. As temperaturas de $32^{\circ} \mathrm{C}$ e $38^{\circ} \mathrm{C}$, na secagem, permitiram a expressão da qualidade das sementes, enquanto a temperatura de $50^{\circ} \mathrm{C}$ reduziu o seu potencial fisiológico.

PALAVRAS-CHAVE: Oryza sativa L.; composição química de sementes; vigor de sementes.

crescimento do consumo. Uma das alternativas para melhoria da sua produtividade é o investimento na implantação de lavouras com sementes de alta qualidade genética, fisiológica e fitossanitária.

A expressão da qualidade máxima das sementes ocorre durante sua maturidade fisiológica, época ideal para se realizar a colheita. Neste período, porém, as sementes apresentam-se com elevado grau de umidade, o que constitui fator desfavorável ao seu armazenamento (Garcia et al. 2004). A colheita de

1. Trabalho recebido em maio/2012 e aceito para publicação em nov./2012 (nº registro: PAT 18457).

2. Universidade Federal de Pelotas (UFPel), Faculdade de Agronomia Eliseu Maciel, Departamento de Ciência e Tecnologia de Sementes, Pelotas, RS, Brasil. E-mail:nlmenezes@hotmail.com.

3. Universidade Federal de Santa Maria (UFSM), Faculdade de Agronomia, Departamento de Fitotecnia, Santa Maria, RS, Brasil. E-mails: lpasqualli@hotmail.com, apaulabarbieri@yahoo.com.br,mvbio@hotmail.com,g.massuquini@hotmail.com. 
arroz irrigado, para sementes, é realizada com teor de água em torno de 22\% (Mariot 1983), umidade considerada elevada para o armazenamento. Deste modo, a secagem é um processo fundamental para um armazenamento seguro, visando à manutenção da qualidade das sementes.

A secagem de sementes permite a redução do seu teor de água a níveis adequados para o armazenamento, preserva as sementes de alterações físicas e/ou químicas induzidas pelo excesso de umidade e torna possível a manutenção da qualidade inicial, durante o armazenamento, possibilitando colheitas mais próximas da maturidade fisiológica (Garcia et al. 2004).

$\mathrm{O}$ processo de secagem pode ser realizado de diversas maneiras, porém, requer cuidados especiais, no que diz respeito às temperaturas. Dependendo da espécie, tempo de exposição e método de secagem, temperaturas elevadas podem danificar membranas celulares e desnaturar proteínas, bem como causar fissuras. Tais danos acarretam redução na qualidade física e fisiológica das sementes, seja logo após a secagem (efeito imediato) ou durante o armazenamento (efeito latente) (Villela \& Peske 2003).

O aquecimento excessivo das sementes, durante a secagem, pode provocar danos, como redução na percentagem e velocidade de germinação, formação de plântulas anormais, trincamentos internos, rompimento do tegumento e alteração da coloração, como observaram Nellist \& Hughes (1973), sendo que a extensão dos danos depende da interação entre temperatura, tempo de exposição e teor de água da semente. De acordo com Menezes et al. (2012), o aumento nas temperaturas de secagem resulta em aumento na percentagem de sementes com fissuras, que, associado a outros efeitos de secagem, afetam, negativamente, a germinação.

Além da importância dos parâmetros do processo de secagem, a composição química das sementes também é de interesse para a tecnologia de sementes, pois influi tanto no vigor, quanto na velocidade de secagem (Garcia et al. 2004) e no potencial de armazenamento. Diferenças no vigor, associadas às características das sementes, são, geralmente, atribuídas à composição química, principalmente com relação à quantidade de reservas, ou à eficiência no metabolismo (Bortolotto et al. 2008).

Lotes com maior qualidade fisiológica apresentam maior teor de proteína bruta, visto que o primeiro evento bioquímico verificado, quando as sementes são expostas a condições desfavoráveis de ambiente, é o dano à síntese de proteínas (Carvalho \& Nakagawa 2000, Bortolotto et al. 2008).

Assim, este estudo objetivou avaliar o efeito de diferentes temperaturas de secagem na integridade física, qualidade fisiológica e composição química de sementes de arroz irrigado.

\section{MATERIAL E MÉTODOS}

O trabalho foi realizado no Laboratório Didático e de Pesquisa em Sementes da Universidade Federal de Santa Maria (RS), utilizando-se sementes de arroz (Oryza sativa L.) das cultivares IRGA 417 e IRGA 420, produzidas na safra agrícola 2008/2009. Vinte quilogramas de sementes de cada cultivar foram colhidos 35 dias após a floração plena. As sementes recém-colhidas foram divididas em quatro lotes, para cada cultivar, os quais foram secos em secador marca Intecnial, modelo S.A.C-18, pelo método estacionário, utilizando-se as seguintes temperaturas: $32^{\circ} \mathrm{C}, 38^{\circ} \mathrm{C}, 44^{\circ} \mathrm{C}$ e $50^{\circ} \mathrm{C}$. Para as temperaturas mais baixas, o período de secagem foi de, aproximadamente, 4 horas e, para a mais alta, de 2,5 horas. Após a secagem, as sementes permaneceram em câmara fria, até o início das avaliações (14 dias), para evitar alterações na qualidade fisiológica.

Adotou-se o delineamento inteiramente casualizado, em esquema fatorial $2 \times 4$ (cultivares de arroz $\mathrm{x}$ temperaturas de secagem), com quatro repetições. A integridade física das sementes foi determinada por meio do teor de água, avaliado antes e após a secagem, de acordo com as Regras para Análise de Sementes - RAS (Brasil 2009), e da percentagem de fissuras, após os tratamentos de secagem. As fissuras foram determinadas em quatro repetições de 25 sementes por tratamento, das quais se retiraram, manualmente, as glumelas, sendo, em seguida, analisadas com o auxílio de uma lupa, com aumento de dez vezes, quanto à presença ou ausência de fissuras, sendo os resultados expressos em percentagem.

A qualidade fisiológica foi determinada por meio de teste de germinação, primeira contagem, envelhecimento acelerado, teste de frio sem solo, comprimento total e fitomassa seca de plântulas.

$O$ teste de germinação foi conduzido com quatro repetições de 100 sementes, para cada tratamento. As sementes foram semeadas em rolos de papel umedecido (2,5 vezes a sua massa) e mantidos em germinador regulado à temperatura constante de $25^{\circ} \mathrm{C}$, durante todo o período de realização do teste. 
As contagens foram realizadas aos 5 e 14 dias após o início do teste, segundo critérios estabelecidos pelas RAS (Brasil 2009). A primeira contagem de germinação foi realizada juntamente com o teste de germinação, determinando-se a percentagem de plântulas normais, no quinto dia após a instalação do teste.

No envelhecimento acelerado, foram utilizadas quatro repetições de 100 sementes, para cada tratamento, as quais foram dispostas em camada única e distribuídas sobre uma tela de alumínio, fixada no interior de uma caixa plástica do tipo "gerbox", com dimensões de $11,0 \mathrm{~cm}$ x 11,0 cm x 4,0 cm, funcionando como um compartimento individual (minicâmara). No interior desta, foram adicionados $40 \mathrm{~mL}$ de água destilada e, a seguir, as caixas foram levadas para a câmara de envelhecimento, à temperatura constante de $41^{\circ} \mathrm{C}$ e $100 \%$ de umidade relativa do ar, por um período de 96 horas (AOSA 1983). Após este período, as sementes foram colocadas para germinar, conforme metodologia descrita para o teste de germinação.

$\mathrm{O}$ teste de frio foi realizado com quatro repetições de 100 sementes, distribuídas em rolos de papel umedecido com quantidade de água equivalente a 2,5 vezes a massa do papel seco. Após a semeadura, os rolos foram colocados em sacos plásticos e vedados com fita adesiva, sendo mantidos em câmara regulada a $10^{\circ} \mathrm{C}$, durante sete dias. Após este período, os rolos foram transferidos para um germinador, à temperatura constante de $25^{\circ} \mathrm{C}$, onde permaneceram por cinco dias, conforme metodologia descrita por Barros et al. (1999). A interpretação foi feita computando-se a percentagem de plântulas normais.

O comprimento total e a massa da matéria seca da plântula foram determinados em 20 sementes de cada uma das quatro repetições. As sementes de cada tratamento foram semeadas no terço superior do substrato rolo de papel. Dentre estas, 15 plântulas escolhidas aleatoriamente foram mensuradas, aos sete dias, com o auxílio de uma régua graduada em milímetros (Nakagawa 1999). Após esta etapa, as plântulas foram secas em estufa regulada a $65^{\circ} \mathrm{C}$, até se obter massa constante (48 horas), determinando-se, assim, a massa da matéria seca da plântula, após a pesagem e divisão pelo número de plântulas.

A composição química das sementes foi avaliada por meio das frações massa seca, proteína e fibra bruta e extrato etéreo. A fração massa da matéria seca foi determinada em estufa, a $105^{\circ} \mathrm{C}$, até massa constante. A fração proteica foi obtida pela determinação da percentagem de nitrogênio total da amostra, segundo método de Kjeldahl, descrito pela AOAC (1997), multiplicada pelo fator médio 6,25. A determinação do extrato etéreo e da fibra bruta seguiram metodologia descrita pela AOAC (1997).

Os dados obtidos em cada teste foram submetidos à análise de variância, com o auxílio do Sistema de Análise Estatística Sanest (Zonta \& Machado 1984). Para analisar os efeitos das temperaturas de secagem, aplicou-se a análise de regressão polinomial. As variáveis cujos resultados foram expressos em percentagem tiveram seus valores transformados em arco seno $\sqrt{\mathrm{x}} / 100$.

\section{RESULTADOS E DISCUSSÃO}

Houve interação entre as cultivares e temperaturas de secagem utilizadas, para as variáveis primeira contagem da germinação, comprimento de plântula, percentagem de fissuras, proteína bruta, fibra bruta e extrato etéreo, demonstrando que o comportamento das cultivares varia com a temperatura de secagem utilizada.

As sementes de arroz foram colhidas com graus de umidade de $23,4 \%$ e $24,6 \%$, para as cultivares IRGA 417 e IRGA 420, respectivamente. Após a secagem, as sementes apresentaram graus de umidade que variaram de $12,6 \%$ a $13,7 \%$, nas duas cultivares. Umidades nesta faixa de concentração são consideradas adequadas para o armazenamento de sementes de arroz (Baudet 2004).

A percentagem de fissuras induzidas pelas temperaturas de secagem, nas cultivares IRGA 417 e IRGA 420, cresceu linearmente, com o aumento da temperatura de secagem $\left(32-50^{\circ} \mathrm{C}\right)$ (Figura 1). Da mesma forma, Menezes et al. (2012) observaram que, para a secagem a $50^{\circ} \mathrm{C}$, há um significativo aumento no número de sementes com fissuras, que resultam em plântulas anormais ou sementes mortas. Tais resultados corroboram, também, os encontrados por Eichol \& Peres (2008), que afirmaram ocorrer aumento na danificação das sementes, principalmente fissuras internas, quando são utilizadas temperaturas elevadas de secagem. Com base nestas informações, é possível deduzir que a temperatura de $50^{\circ} \mathrm{C}$ foi inadequada para secar lotes de sementes de arroz.

Segundo Motta (1997), os danos causados pela secagem a $50^{\circ} \mathrm{C}$ repercutem nas operações de beneficiamento, tornando as sementes do lote facilmente quebradiças, além de interferirem nos mecanismos 


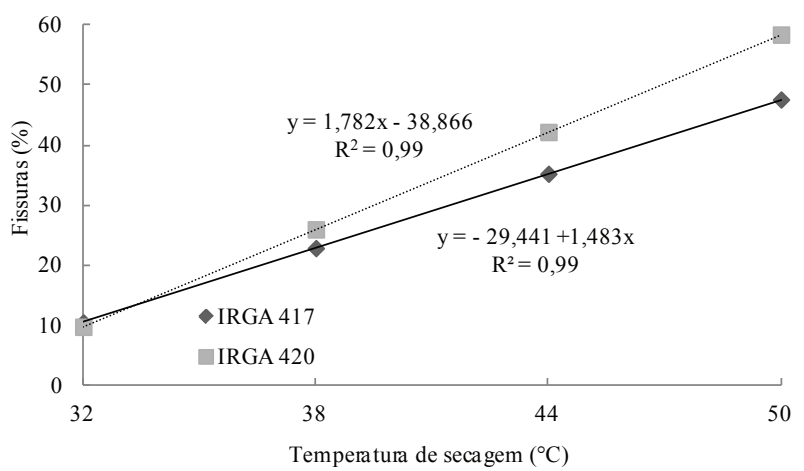

Figura 1. Percentual de fissuras nas sementes de arroz irrigado (cultivares IRGA 417 e IRGA 420), após secagem estacionária em diferentes temperaturas (Santa Maria, RS, 2012).

de trocas hídricas e gasosas, aumentando a predisposição ao ataque de insetos e micro-organismos.

Com relação à qualidade fisiológica das sementes de arroz, avaliada pelo teste de primeira contagem de germinação, tanto para a cultivar IRGA 417 quanto para a IRGA 420, pôde-se constatar que o aumento na temperatura de secagem reduziu a formação de plântulas normais, resultado verificado na avaliação inicial (Figura 2a). Tais resultados corroboram os encontrados por Nellist \& Hughes (1973) e Villela \& Peske (2003), os quais indicaram que o aquecimento excessivo, durante a secagem, por elevado tempo e/ou temperatura de exposição, pode provocar danos que incluem a redução no número de plântulas normais produzidas.

Os dados de comprimento total de plântulas, obtidos para a cultivar IRGA 417 (Figura 2b), permitiram observar diferenças apenas entre os valores absolutos. Plântulas provenientes das sementes secas a $38^{\circ} \mathrm{C}$ apresentaram os menores valores, e aquelas secas a $44^{\circ} \mathrm{C}$ apresentaram os maiores valores, porém, não houve diferença estatística significativa, nas temperaturas testadas. $\mathrm{O}$ crescimento das plântulas, de acordo com Popinigis (1985), é um parâmetro muito variável e fortemente influenciado por fatores genéticos e ambientais.

Para a cultivar IRGA 420 (Figura 2b), o comprimento total das plântulas foi afetado pelas temperaturas de secagem, sendo que a elevação das temperaturas reduziu o comprimento das mesmas. Estes resultados concordam com os encontrados por Höfs et al. (2004), os quais afirmaram que temperaturas elevadas influenciam negativamente no vigor das sementes, afetando o crescimento inicial das plântulas e sua capacidade de acumular biomasssa.

Observou-se que o teor de proteína bruta, nas sementes das duas cultivares, foi significativamente afetado pela temperatura de secagem (Figura 3a). Em relação aos resultados obtidos à temperatura de $32^{\circ} \mathrm{C}$, para a cultivar IRGA 417, verificou-se decréscimo nos valores, quando utilizadas as temperaturas de secagem de $38^{\circ} \mathrm{C}$ e $44^{\circ} \mathrm{C}$, e aumento destes, quando utilizada a temperatura de $50^{\circ} \mathrm{C}$. Observou-se resposta similar para a cultivar IRGA 420, sendo que o aumento no teor de proteína bruta, à temperatura de $50^{\circ} \mathrm{C}$, foi maior para esta cultivar. Este resultado discorda dos encontrados por Eichelberger et al. (2002), os quais concluíram que temperaturas elevadas afetam a estrutura das proteínas, causando a perda da qualidade fisiológica de sementes de azevém.

Com relação à análise do teor de fibra bruta, observaram-se diferenças significativas entre as temperaturas de secagem, nas duas cultivares (Figura 3b), porém, com comportamentos distintos. Foi possível notar, para a cultivar IRGA 417, que houve manutenção nos valores pertinentes à fibra bruta, nas
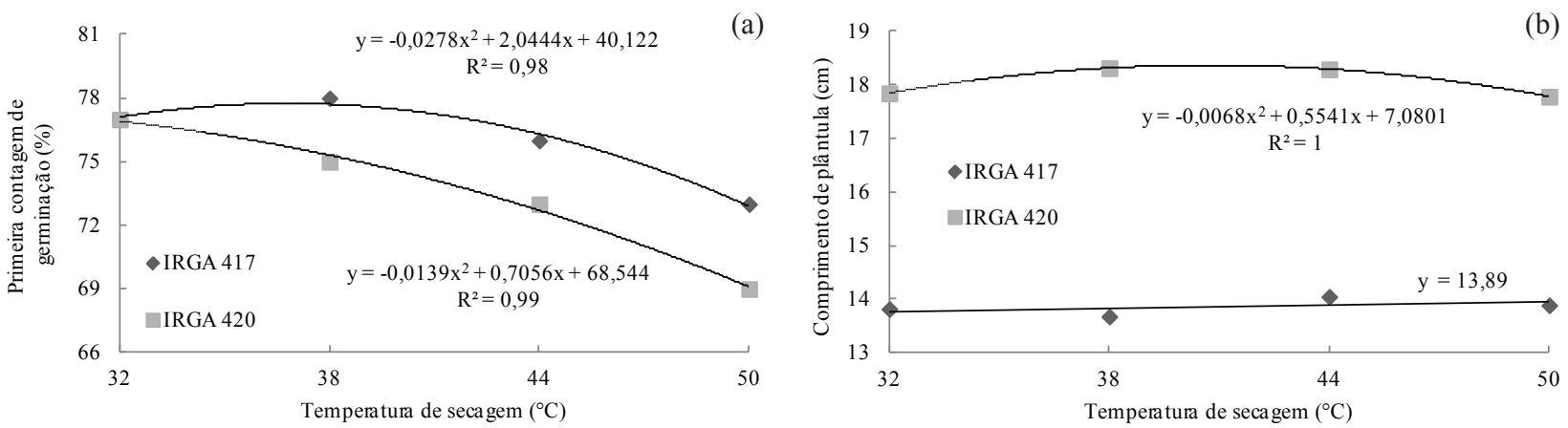

Figura 2. Primeira contagem de germinação (a) e comprimento de plântula (b) das sementes de arroz irrigado (cultivares IRGA 417 e IRGA 420) submetidas a diferentes temperaturas de secagem estacionária (Santa Maria, RS, 2012). 

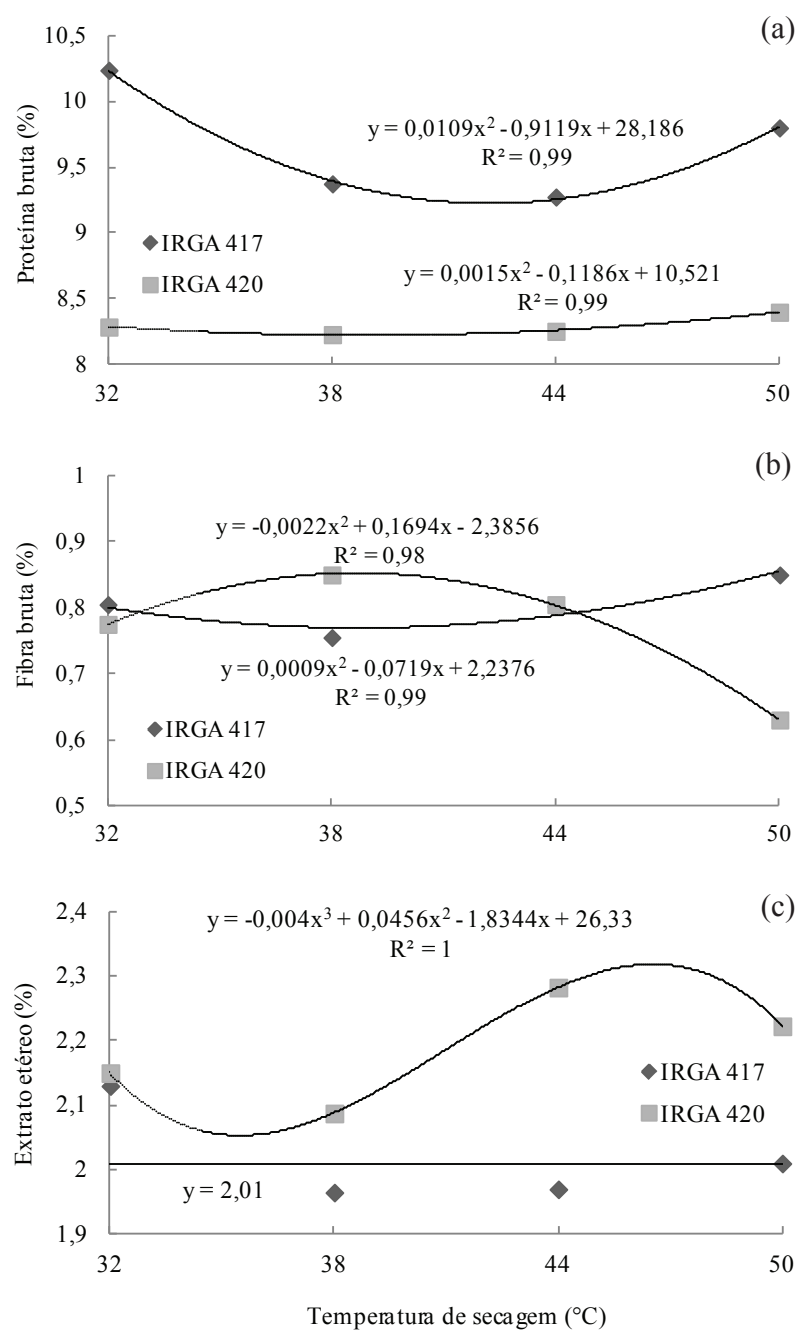

Figura 3. Proteína bruta (a), fibra bruta (b) e extrato etéreo (c) das sementes de arroz irrigado (cultivares IRGA 417 e IRGA 420) submetidas a quatro temperaturas de secagem estacionária (Santa Maria, RS, 2012).

sementes submetidas à secagem com temperatura de $50^{\circ} \mathrm{C}$, e que houve decréscimo nos valores desta variável, quando as temperaturas empregadas foram de $38^{\circ} \mathrm{C}$ e $44^{\circ} \mathrm{C}$. A cultivar IRGA 420 , por outro lado, apresentou incremento no teor de fibra bruta, quando utilizadas as temperaturas de $38^{\circ} \mathrm{C}$ e $44^{\circ} \mathrm{C}$, e decréscimo, quando a temperatura foi de $50^{\circ} \mathrm{C}$.

Os resultados da análise do teor de extrato etéreo, para a cultivar IRGA 417 (Figura 3c), não permitiram o ajuste de uma equação para explicar o efeito das temperaturas de secagem sobre este componente. A análise dos dados mostra que houve efeito significativo das temperaturas de secagem sobre o teor de extrato etéreo da cultivar IRGA 420 (Figura 3c). Para esta cultivar, observou-se que o menor valor foi obtido nas sementes que foram submetidas à secagem a $38^{\circ} \mathrm{C}$, e os maiores valores para aquelas secas a $44^{\circ} \mathrm{C}$ e $50^{\circ} \mathrm{C}$. Resultados semelhantes, para esta variável, foram encontrados em sementes de milho, quando submetidas a diferentes temperaturas, em secagem estacionária (Dionello et al. 2000), sendo observados os maiores valores nas temperaturas mais elevadas de secagem. Os autores atribuíram estes resultados à velocidade e intensidade do processo deteriorativo das sementes, pela ação das elevadas temperaturas de secagem.

Pôde-se observar que houve efeito significativo, para o fator temperatura de secagem, para as variáveis germinação, teste de frio e envelhecimento acelerado, evidenciando que as temperaturas de secagem testadas afetaram a qualidade das sementes, independentemente da cultivar de arroz utilizada (Figura 4).

Por meio dos resultados do teste de germinação, pôde-se verificar que a germinação das sementes permaneceu acima dos padrões mínimos para comercialização de sementes no Brasil (Brasil 2005), que é de $80 \%$, apenas nas temperaturas de $32^{\circ} \mathrm{C}$ e $38^{\circ} \mathrm{C}$, sendo reduzida, consideravelmente, nas temperaturas mais elevadas (Figura 4a).

As temperaturas de $44^{\circ} \mathrm{C}$ e $50^{\circ} \mathrm{C}$ produziram aumento significativo no percentual de fissuras e considerável decréscimo na germinação das sementes. Provavelmente, este efeito esteja relacionado à associação das fissuras com os danos fisiológicos produzidos pelas altas temperaturas. Estes resultados vão de encontro aos de Villela \& Peske (2003), que indicaram que a extensão dos danos é dependente da temperatura e do tempo de exposição das sementes, afirmação também enfatizada por Brooker et al. (1974), que apontaram, como temperaturas máximas de secagem, aquelas compreendidas entre $40,5^{\circ} \mathrm{C}$ e $43,3^{\circ} \mathrm{C}$.

Verificou-se efeito significativo das temperaturas de secagem sobre a formação de plântulas normais, no teste de envelhecimento acelerado (Figura 4b). Este resultado permite inferir sobre a qualidade das sementes, após a secagem, tendo-se em vista que, quando expostas a condições de estresse, como as encontradas no teste de envelhecimento acelerado, houve redução linear no vigor das sementes, à medida em que ocorreu elevação da temperatura de secagem. A maior e a menor percentagem de plântulas normais foram observadas nas sementes 

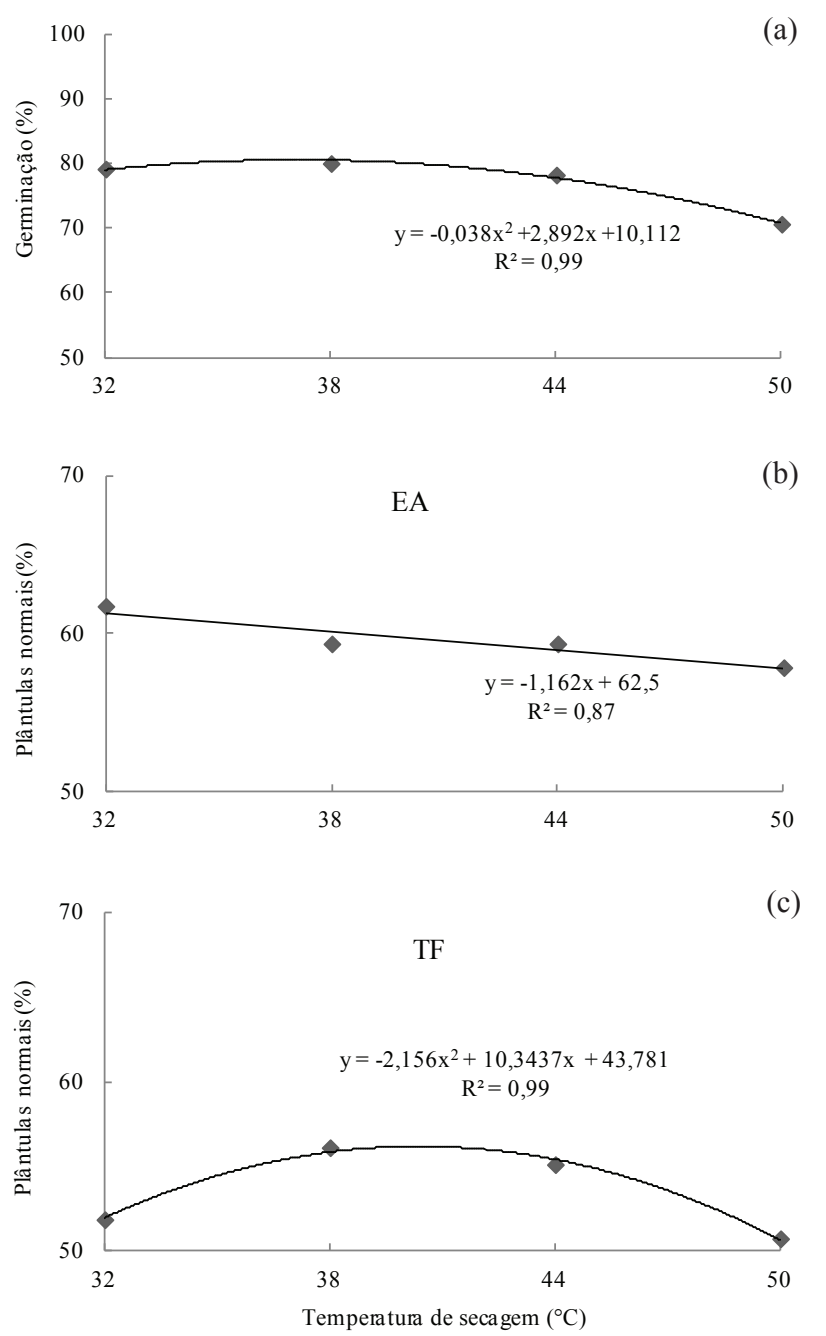

Figura 4. Germinação, plântulas normais no envelhecimento acelerado (EA) e plântulas normais no teste de frio (TF) das sementes de arroz irrigado submetidas a diferentes temperaturas de secagem estacionária (Santa Maria, RS, 2012).

provenientes da secagem às temperaturas de $32^{\circ} \mathrm{C}$ e $50^{\circ} \mathrm{C}$, respectivamente.

Estes resultados permitem concluir que, quanto mais elevada a temperatura de secagem, maior será o decréscimo na qualidade das sementes. Tal informação é ratificada por Lima (1997), o qual verificou que, nos lotes de menor qualidade, ocorre maior redução no potencial fisiológico, quando expostos a condições de estresse, como o teste de envelhecimento acelerado.

No teste de frio, verificou-se efeito significativo das temperaturas de secagem sobre o vigor das sementes, em que a maior percentagem de plântulas normais foi observada nas sementes provenientes da secagem com temperatura de $38^{\circ} \mathrm{C}$ (Figura $4 \mathrm{c}$ ). Além disto, observou-se, neste teste, a mesma tendência identificada nos testes de germinação e primeira contagem, em que as temperaturas de $44^{\circ} \mathrm{C}$ e $50^{\circ} \mathrm{C}$ reduziram a qualidade das sementes. Tais resultados permitem inferir que as temperaturas elevadas, estudadas no presente trabalho, provocaram danificações mais acentuadas às sementes do que as menores temperaturas, o que corrobora o observado por Saravia et al. (2007), ao destacarem a eficiência deste teste, na avaliação da qualidade fisiológica de sementes de arroz.

Os resultados obtidos por meio da avaliação da qualidade fisiológica, de maneira geral, permitiram verificar que o emprego de temperatura de secagem até $38^{\circ} \mathrm{C}$ não causa efeitos imediatos prejudiciais à qualidade fisiológica de sementes de arroz. Entretanto, o uso de temperaturas acima de $38^{\circ} \mathrm{C}$, como as de $44^{\circ} \mathrm{C}$ e $50^{\circ} \mathrm{C}$, estudadas no presente trabalho, ocasiona danos imediatos à qualidade de sementes de arroz.

\section{CONCLUSÕES}

1. O aumento na temperatura de secagem estacionária, na faixa de $32^{\circ} \mathrm{C}$ a $50^{\circ} \mathrm{C}$, aumentou, também, a percentagem de fissuras em sementes de arroz irrigado, sendo a cultivar IRGA 420 mais sensível às fissuras do que a IRGA 417.

2. Secagens realizadas até a temperatura de $38^{\circ} \mathrm{C}$, pelo modo estacionário, não afetaram a qualidade das sementes das cultivares de arroz avaliadas, enquanto a temperatura de $50^{\circ} \mathrm{C}$ reduziu o seu potencial fisiológico.

3. Para ambas as cultivares, as temperaturas de secagem estudadas não afetaram a composição química das sementes de arroz.

\section{REFERÊNCIAS}

ASSOCIATION OF OFFICIAL ANALYTICAL CHEMISTS (AOAC). Official methods of analysis of AOAC International. 16. ed. Gaitheersburg: AOAC, 1997.

ASSOCIATION OF OFFICIAL SEED ANALYSTS (AOSA). Seed vigour testing handbook. Lincoln: AOSA, 1983.

BARROS, A. S. R. et al. Testes de frio. In: KRZYZANOWSKI, F. C.; VIEIRA, R. D.; FRANÇA NETO, J. B. Vigor de sementes: conceitos e testes. Londrina: Abrates, 1999. p. 5.1-5.15. 
BAUDET, L. M. L. Armazenamento de sementes de arroz irrigado. In: PESKE, S. T.; SCHUCH, L. O. B.; BARROS, A. C. S. A. Produção de sementes de arroz irrigado. Pelotas: UFPel, 2004. p. 481-498.

BORTOLOTTO, R. P. et al. Teor de proteína e qualidade fisiológica de sementes de arroz. Bragantia, Campinas, v. 67, n. 2 , p. 513-520, 2008.

BRASIL. Ministério da Agricultura, Pecuária e Abastecimento. Instrução normativa $\mathrm{n}^{\circ} 25$, de 16 de dezembro de 2005. Padrões para produção e comercialização de sementes de arroz. Diário Oficial da República Federativa do Brasil, Brasília, DF, 20 dez. 2005. Disponível em: <http://www.agricultura.pr.gov.br/ arquivos/File/PDF/padroes_arroz.pdf $>$. Acesso em: 19 mar. 2011.

BRASIL. Ministério da Agricultura e Reforma Agrária. Regras para análise de sementes. Brasília, DF: SNDA/ DNDV/CLAV, 2009.

BROOKER, D. B.; BAKKER-ARKEMA, F. W.; HALL, C. W. Drying cereal grains. Westport: AVI, 1974.

CARVALHO, N. M.; NAKAGAWA, J. Sementes: ciência, tecnologia e produção. 4. ed. Jaboticabal: Funep, 2000.

DIONELLO, R. G. et al. Temperatura do ar na secagem estacionária e tempo de armazenamento na qualidade de grãos de milho. Revista Brasileira de Agrociência, Pelotas, v. 6, n. 2, p. 137-143, 2000.

EICHELBERGER, L. et al. Composição química de sementes de azevém em resposta ao retardamento da secagem e ao armazenamento. Pesquisa Agropecuária Brasileira, Brasília, DF, v. 37, n. 5, p. 693-701, 2002.

EICHOL, E. D.; PERES, W. B. Monitoramento da qualidade física de secagem de sementes de milho em secadores estacionários. Revista Brasileira de Sementes, Londrina, v. 30, n. 2, p. 57-64, 2008.

EMPRESA BRASILEIRA DE PESQUISA AGROPECUÁRIA (Embrapa). Importância econômica, agricola e alimentar do arroz. 2009. Disponível em: <http://sistemasdeproducao.cnptia.embrapa.br/ FontesHTML/Arroz/ArrozIrrigadoBrasil/cap01.htm>. Acesso em: 10 mar. 2010.

GARCIA, D. C. et al. A secagem de sementes. Ciência Rural, Santa Maria, v. 34, n. 2, p. 603-608, 2004.
HÖFS, A. et al. Emergência e crescimento de plântulas de arroz em resposta à qualidade fisiológica de sementes. Revista Brasileira de Sementes, Pelotas, v. 26, n. 1, p. 9297, 2004.

LIMA, D. Influência da alta temperatura de secagem em sementes de arroz. 1997. 92 f. Tese (Doutorado em Ciência e Tecnologia de Sementes) - Faculdade de Agronomia Eliseu Maciel, Universidade Federal de pelotas, Pelotas, 1997.

MARIOT, C. Produção de semente genética, pré-básica e básica de arroz irrigado. Lavoura Arrozeira, Porto Alegre, v. 36, n. 346, p. 29-36, 1983.

MENEZES, N. L. et al. Using X-Rays to evaluate fissures in rice seeds dried artificially. Revista Brasileira de Sementes, Londrina, v. 34, n. 1, p. 70-77, 2012.

MOTTA, W. A. Adaptação do método contínuo de secagem para sementes de arroz. 1997. 58 f. Dissertação (Mestrado em Ciência e Tecnologia de Sementes) - Universidade Federal de Pelotas, Pelotas, 1997.

NAKAGAWA, J. Testes de vigor baseados no desempenho das plântulas. In: KZYZANOWSKI, F. C.; VIEIRA, R. D.; FRANÇA NETO, J. Vigor de sementes: conceitos e testes. Londrina: Abrates, 1999. p. 2.1-2.21.

NELLIST, M. E.; HUGHES, M. Physical and biological processes in the drying of seed. Seed Science and Technology, Zurich, v. 1, n. 1, p. 613-643, 1973.

POPINIGIS, F. Fisiologia da semente. Brasília, DF: Agiplan, 1985.

SARAVIA, C. T.; PERES, W. B.; RISSO, J. Manejo da temperatura do ar na secagem intermitente de sementes de arroz irrigado. Revista Brasileira de Sementes, Pelotas, v. 29, n. 2, p. 23-27, 2007.

VILLELA, F. A.; PESKE, S. T. Secagem de sementes. In: PESKE, S.; ROSENTHAL, M.; ROTA, G. (Eds.). Sementes: fundamentos científicos e tecnológicos. Pelotas: UFPel, 2003. p. 283-321.

ZONTA, E. P.; MACHADO, A. A. Sistema de análise estatística para microcomputadores (Sanest). Pelotas: UFPel, 1984. 